\title{
Antalya ilinde Genç Çiftçi Projesinin uygulaması ve sürdürülebilirliği üzerine bir araştırma
}

\section{A research on the application and sustainability of Young Farmers Project in the Antalya province}

\author{
Ahmet ALKAN1®i, Burhan ÖZKAN²i \\ ${ }^{1}$ Akdeniz Üniversitesi, Fen Bilimleri Enstitüsü, Tarım Ekonomisi Anabilim Dalı, 07059, Antalya \\ ${ }^{2}$ Akdeniz Üniversitesi, Ziraat Fakültesi, Tarım Ekonomisi Bölümü, 07059, Antalya \\ Sorumlu yazar (Corresponding author): B. Özkan, e-posta (e-mail): bozkan@akdeniz.edu.tr \\ Yazar(lar) e-posta (Author e-mail): ahmetalkan07@gmail.com
}

\section{MAKALE BİLGİSI}

Alınıș tarihi 16 Eylül 2019

Düzeltilme tarihi 29 Kasım 2019

Kabul tarihi 28 Şubat 2020

\section{Anahtar Kelimeler:}

Çiftçi

Genç Çiftçi Projesi

Kırsal kalkınma

Sürdürülebilir tarımsal üretim

Antalya

\begin{abstract}
$\ddot{O Z Z}$
$\mathrm{Bu}$ araștırmanın amacı; Antalya ilinde Genç Ciftçi Projesi (GCP) uygulamasının sürdürülebilirlik, kırsal nüfusun istihdamı, çiftçilerin gelir düzeyinin arttırılması gibi hedeflerinin, gerçekleşme potansiyelini ve sürdürülebilirliğini değerlendirmektir. Araştırmanın ana materyalini, araștırma kapsamına alınan 10 ilçede GÇP'den yararlanan 127 genç çiftçi ile 2018 yılında yapılan yüz yüze anket verileri oluş̧urmuştur. Çalışmada çiftçilerden elde edilen veriler kullanılarak GCP uygulamasının güçlü ve zayıf yönleri ile firsat ve tehditlerine göre GZFT analizi yapılmıştır. Araştırma kapsamındaki çiftçilerin $\% 15$ 'i erkek ve $\% 85$ 'i kadın olup çiftçilerin yaklaşı \%62'si hayvansal üretim, \%38'i bitkisel üretim yapmaktadır. Görüşme yapılan çiftçilerin büyük çoğunluğu gelirini arttırmak için GÇP'ye başvurdukları belirlenmiştir. Projeden yararlanan çiftçilerin $\% 85$ gibi büyük çoğunluğu projeyi yararlı görmektedir. Diğer yandan çiftçilerin \%14.2'si GÇP ile tarımsal üretime başladığını belirtmişlerdir. Araştırmadan elde edilen sonuçlara göre çiftçiler tarafindan GÇP uygulaması yararlı bir proje olarak kabul edilmektedir.
\end{abstract}

\section{ARTICLE INFO}

Received 16 September 2019

Received in revised form 29 November 2019 Accepted 28 February 2020

\section{Keywords:}

Farmer

Young Farmers Project

Rural development

Sustainable agricultural production

Antalya

\begin{abstract}
This research aims to evaluate the realization potential and sustainability of the targets of Young Farmers Project (YFP) in Antalya in terms of such as sustainability, employment of rural population and increasing the income level of young farmers. The data was collected from 127 young farmers located in 10 counties of Antalya Province, by using face to face survey in 2018. In the study, SWOT analysis was conducted based on the strengths, weaknesses, opportunities and threats of YFP application by using data obtained from farmers who benefited from the YFP in 2016. The research results showed that $15 \%$ and $85 \%$ of the farmers were male and female respectively. It is about $62 \%$ of the farmers engaged in animal production and $38 \%$ of them produce the crop. It was found that the majority of the farmers interviewed applied to the YFP to increase their income. As many as $85 \%$ of the farmers benefiting from the project consider the project beneficial. On the other hand, $14.2 \%$ of farmers stated that they started agricultural production with YFP. According to the results of the research, YFP, the implementation is considered as a useful project by farmers.
\end{abstract}

\section{Giriş}

Tarım ve Orman Bakanlığı (TOB); genç çiftçilerin girişimciliğinin desteklenmesi, alternatif gelir kaynaklarının oluşturulması, gelir düzeyinin yükseltilmesi, tarımda sürdürülebilirliğin sağlanması ve kırsalda yaşayan genç nüfusun istihdamına katkı sağlayacak tarımsal üretime yönelik projelerin desteklenmesi amacıyla Genç Çiftçi Projelerinin (GÇP) Desteklemesi için hibe destek programı başlatmıştır. Bu amaçla kırsal kalkınma destekleri kapsamında GÇP'lerinin desteklenmesine ilişkin teblĭg 05 Nisan 2016 tarihinde yayımlanarak Resmi Gazete'de yürürlüğe girmiştir (TCRG 2016).

GÇP'ye başvurularda, hibe sözleşmesi imzalanarak belirlenen şartların gerçekleşmesi durumunda her çiftçiye en fazla 30.000 TL'ye kadar hibe yoluyla destek sağlanmaktadır. GÇP başvurularının değerlendirilmesinde gazi, şehit yakını, 
engelli, kadın ve eğitim sertifikası sahibi olan genç çiftçilere pozitif ayrımcılık yapılmaktadır (TOB 2018a).

2016 yılı verilerine göre Antalya ilinde 18 ilçede GÇP'ye yönelik çeşitli üretim faaliyetlerine hibe desteği sağlanmıştır. Proje kapsamında hibe desteği alan 213 genç çiftçinin 146's1 hayvansal üretim, 67'si ise bitkisel üretime yönelik hibe desteğinden faydalanmıştır. Halen, GÇP uygulaması Antalya ilinde hayvansal üretim, bitkisel üretim, tıbbi ve aromatik bitki üretimi projelerinde uygulanmaktadır.

$\mathrm{Bu}$ araştırmada, GÇP'nin Antalya ilinde uygulaması ve sürdürülebilirliğinin incelenmesi amaçlanmıştır. $\mathrm{Bu}$ amaca yönelik olarak çalışmada, GÇP'nin sürdürülebilirlik, kırsal nüfusun istihdamı ve genç çiftçilerin gelir düzeyinin artırılması gibi hedeflerinin, projeden yararlanan çiftçilerin görüşleri esas alınarak değerlendirmesi yapılmıştır.

\section{Materyal ve Yöntem}

Araştırmanın ana materyalini, Antalya ilinde 2016 yılı GÇP hibe desteklerinden faydalanan 127 genç çiftçi ile yapılan anketlerden elde edilen birincil veriler oluşturmuştur. Çalışmada GÇP'den yararlanan çiftçiler esas alınarak, Antalya ilindeki 10) ilçe belirlenmiş ve bu ilçelerdeki GÇP'den yararlanan çiftçilerin tamamı araştırma kapsamına alınmıştır. Dolayısıyla araştırma Aksu, Döşemealtı, Elmalı, Finike, Kemer, Kepez, Korkuteli, Kumluca, Manavgat ve Serik ilçelerinde yürütülmüştür. Görüşme yapılan çiftçiler ve iletişim adresleri Tarım ve Orman Bakanlığı Antalya İl Müdürlüğü'nden temin edilmiştir (TOB 2017).

Görüşme yapılan çiftçilerin seçiminde araştırma alanında uygulanan GÇP sayısı esas alınmıştır. Buna göre en çok hibe desteği alan büyükbaş hayvancılık, küçükbaş hayvancılık, arıcılık, örtü altı tesisi sebze yetiştiriciliği ve mantarcılık projeleri araştırma kapsamına alınmıştır.

Üreticilerden verilerin toplanmasında kullanılan anket formu beş bölümden oluşmuştur. İlk bölümde çiftçilerin demografik özellikleri, ikinci bölümde işletmenin özellikleri, üçüncü bölümde GÇP uygulaması ve etkileri, dördüncü bölümde GÇP uygulamasında karşılaşılan sorunlar ve son bölümde ise GÇP ile ilgili görüş ve düşüncelere yer verilmiştir.

Araştırmada elde edilen verilerin SPSS programında frekans ve ortalamalar üzerinden betimsel analizi ve GZFT (SWOT) analizi yapılmıştır. Çiftçilere ait demografik ve tanımlayıcı verileri yorumlamada, yüzde ve frekans kullanılmıştır. GÇP'nin uygulaması ve sürdürülebilirliğine ilişkin GZFT analizi ile çiftçilerden elde edilen verilerden yararlanarak güçlü, zayıf yönler, firsatlar ve tehditler belirlenmiştir.

GZFT analizi, bilimsel olarak durum analizi yapmaya imkan veren stratejik önemde bir analiz tekniğidir. Tekniğin uygulanması ile iç ve dış etkenleri esas alınarak, güçlü yönler ve firsatlardan en üst seviyede yararlanmayı sağlayabilecek, tehditlerin ve zayıflıkların etkisini azaltacak strateji ve planlar geliştirilebilmektedir (Çoban ve Karakaya 2010).

Kuruluşun iç analizi yapılırken geçmiş ve mevcut durumu incelenerek sorunlarının tespiti ve potansiyelinin ortaya konulması sağlanmaktadır. İç değerlendirme, kuruluşun güçlü yönlerini belirleyerek ilerideki hedeflerine yönelmesi ve zayıf yönlerine karşın tedbirler alması için önemlidir. GZFT analizinde dış durum analizi ise kuruluşun bulunduğu çevreyi tanıması içindir. Dış çevre analizi, çevre ve bağlantıda bulunulması mümkün olan faktörler hakkında doğru ve tutarlı bilgi toplama işlemlerini de içine almaktadır. Fırsat, bir faaliyet için en uygun zamanın meydana gelmesi demektir. Tehdit ise kuruluşun hedef ve amaçlarına ulaşmasını zorlaştıran, engel olan durumu ifade etmektedir (Çizelge 1). Kuruluşun gelecek hedeflerini belirlemede firsatlar büyük öneme sahibi olurken, hedeflere engel olmaması için tehditleri takip ederek, tedbirler alması gerekmektedir (Çoban ve Karakaya 2010; Sav ve Sayın 2015).

Çizelge 1. GZFT matrisi.

Table 1. SWOT matrix.

\begin{tabular}{ccc}
\hline İç ve Dış Kaynaklar & Faydalı & Zararlı \\
\hline $\begin{array}{c}\text { İç Kaynak } \\
\text { (Kuruluşun nitelikleri) } \\
\text { Dış Kaynak }\end{array}$ & Güçlü Yönler & Zayıf Yönler \\
(Çevrenin nitelikleri) & Fırsatlar & Tehditler \\
\hline
\end{tabular}

\section{Bulgular ve Tartışma}

Araştırma kapsamında görüşme yapılan 127 çiftçinin \%85.0'i kadın, \%97.6'sının evli ve \%6.3'ünün ise şehit yakını/gazi/engelli olduğu belirlenmiştir. Kadınların çoğunlukta olmasında, kadınlara pozitif ayrımcılık yapılması ve GÇP değerlendirme kriterinde kadın girişimciye +5 puan verilmesinin önemli rol oynadığı söylenebilir. Benzer şekilde başvuru şartlarında evli ve şehit yakını/gazi/engelli olanlara da +5 puan verilmesinin de başvuruda etkili olduğu ifade edilebilir.

Adana ilinde yapılan bir araştırmaya göre GÇP'den faydalanan çiftçilerin \%82.6'sı kadın ve \%88.1'inin evli olduğu saptanmıştır (TOB 2018b). Buna göre GÇP projesi konusunda Antalya ve Adana'da yürütülen çalışmalarda cinsiyet dağılımı ve evlilik durumu açısından benzer sonuçlar bulunmuştur.

Kadın çiftçilerin tarımsal üretime işletme sahibi olarak katılması genç kadınların istihdamına katkı sağlamada önemlidir. Dolayısıyla projede kadın girişimcilerin daha çok desteklenmesi ve pozitif ayrımcılık yapılarak hibe desteğinden daha fazla yararlandırılması ile kırsaldaki kadın-erkek girişimci dengesinin sağlanması hedeflenmektedir.

Araştırma kapsamında görüşme yapılan çiftçilerin; \%46.5'si ilkokul, \%40.2'si ise ortaokul, mezunu olduğu belirlenmiştir. Buna göre projeden yararlanan çiftçilerin yaklaşık yarısı ilkokul mezunudur.

Unakıtan ve Başaran (2018), tarafindan yürütülen çalışmada, Tekirdağ ilinde GÇP'nden faydalanan çiftçilerin \%48.3'ünün ilkokul mezunu olduğunu ifade edilmiştir.

$\mathrm{Bu}$ bulgulara göre; Antalya ve Tekirdağ ilinde GÇP'den faydalanan çiftçilerin yarısının eğitim düzeylerinin ilköğretim seviyesindedir. Dolayısıyla tarımsal üretimde verimliliğin arttırılması ve sürdürülebilirliğin sağlanması açısından; çiftçilere tarımsal üretim konularında eğitim verilmesinin gerekli olduğu söylenebilir. GÇP kapsamında böyle bir politikanın izlenmesi, çiftçilerin tarımsal üretime devam etmesi ve kırsalda kalması yönünden katkı yapabilecektir.

Araştırma kapsamında görüşülen çiftçilerin \%21.3'ü 1-5 yıl süredir çiftçilik yaparken, \%78.7'si ise 5 yıldan fazla süredir çiftçilik yapmaktadır. Çiftçilerin \%33.1'i sosyal güvence kapsamındayken, \%66.9'unun sosyal güvencesi bulunmamaktadır. Anket sonuçlarına göre çiftçilerin; \%11.0'inin 2.000 TL ve üstü aylık geliri, \%89.0'u gibi büyük çoğunluğunun ise $2.000 \mathrm{TL}$ altında aylık geliri olduğu belirlenmiştir.

Görüşme yapılan çiftçilerin $\% 20.5$ 'i tarımsal üretim faaliyeti ile ilgili eğitim aldıklarını belirtirken, çiftçilerin 
yalnızca \%2.4'ü GÇP ile ilgili eğitim almışlardır. Adana ilinde yürütülen çalışmada ise çiftçilerin \%30.3'ünün tarımsal üretim ilgili eğitim aldıkları belirlenmiştir (TOB 2018c). Bu sonuçlara göre GÇP'den yararlanan çiftçilerin yaklaşık 1/3'ünün tarımsal eğitim alırken, çiftçilerin GÇP ile ilgili eğitim alma oranı ise oldukça düşüktür. Dolayısıyla, GÇP'nin amaçlarına ulaşabilmesi için projeden yararlanan çiftçilere yönelik tarımsal eğitim verilmesine ihtiyaç olduğu ifade edilebilir.

Araştırma sonuçlarına göre çiftçilerin \%61.4'ünün hibe desteği almadan önce tarımsal işletmeye sahip oldukları belirlenmiştir. Görüşme yapılan çiftçilerin \%44.1'i büyükbaş hayvancılık, \%33.9'u örtü altı yetiştiriciliği, \%12.6's1 ise küçükbaş hayvancılık, \%5.5'i arıcılık ve \%3.9'u mantar üretimi projesi desteği almıştır (Çizelge 2).

Çizelge 2. Araştırma kapsamındaki uygulama GÇP'leri.

Table 2. Application YFPs within the scope of the research.

\begin{tabular}{ccc}
\hline Projeler & Sayı & \% \\
\hline Örtü altı yetiştiriciliği & 43 & 33.9 \\
Arıcılık & 7 & 5.5 \\
Mantar üretimi & 5 & 3.9 \\
Büyükbaş hayvancılık & 56 & 44.1 \\
Küçükbaş hayvancılık & 16 & 12.6 \\
\hline Toplam & 127 & 100.0 \\
\hline
\end{tabular}

Proje hibe desteği ile kurulan işletmelerde, arazilerin \%50.4'ünün mülk, \%48.0'i kiracılık ve \%1.6's1 ise ortakçılık yapan işletmelerdir. İşletmelerin \%49.6's1 3-5 dekar, \%48.0'i 3 dekardan az, \%2.4'ü ise 5-10 dekar arasında işletme büyüklüğüne sahiptir. Bu sonuçlara göre, projeden yararlanan işletmelerin küçük işletmeler olduğu anlaşılmaktadır. Araştırma kapsamında çiftçilerin GÇP kapsamındaki tarımsal faaliyetlerinden elde ettikleri ylllık gelirleri de incelenmiştir.
Buna göre çiftçilerin \%41.7'si 5.000 TL altında, \%26.8'i 5.001-10.000 TL aras1 ve \%5.5'i ise 10.000 TL üzeri gelir elde ettikleri belirlenmiştir. İşletmelerin \% 26.0's1 ise üretim faaliyetine yeni geçtikleri için henüz gelir elde etmemektedirler.

Görüşme yapılan çiftçilerin üretimleri ile ilgili bilgi kaynakları farklılaşmaktadır. Buna göre çiftçilerin \%41.7'si İl/ílçe Tarım ve Orman Müdürlügüne ve \%41.7'si ise özel veterinere başvurarak üretim ile ilgili bilgi almaktadır. Görüşme yapılan \%53.5'i internet/TV/gazete ve \%40.2'si İl/İlçe Tarım ve Orman Müdürlüklerinden GÇP konusunda haberdar olmuşlardır. Çiftçilerin hibe desteği alma başvurusuna çoğunlukla (\%57.48) kendileri karar vermektedir. Bunu eşleri ile birlikte karar (\%39.37) verme durumu izlemiştir. Çiftçiler tarafından GÇP'ye başvurma nedenini çoğunlukla (\%74.8) gelir elde etmek ve geliri arttırmak amaçlıdır.

Hibe desteği alma sürecinde en sık karşılaşılan sorunlar, bürokratik engeller (\%55.9) ve başvuru şartları (\%30.72) olarak belirlenmiştir. Bu konuda en büyük sorun hayvancilık üretimi yapan çiftçilerden istenilen uygun ahır yapımı, bitkisel üretim yapanlardan ise plastik sera tesisinin önceden yapılmasının istenilmesi olarak ifade edilmiştir (Çizelge 3 ).

Genç çiftçilerin proje destekleme sürecine ilişkin genel görüşleri incelediğinde; çiftçilerin $\% 85.8$ 'i istenilen evrakları toplamanın zor olduğunu ve \%8.7'si ise başvuru sürecinin uzun olduğunu belirtmişlerdir. Çalışmada çiftçilere GÇP sözleşmesi ile ilgili bilgi düzeyleri de sorulmuştur. Buna göre çiftçilerin \%49.6's1 sözleşme yükümlülüğünü kısmen, \%18.9'u tam olarak bildiklerini belirtirken \%31.5' $\mathrm{i}$ ise hiç bilmediklerini belirtmişlerdir. $\mathrm{Bu}$ sonuç, çiftçilerin 1/3'ünün yapmış oldukları sözleşme yükümlülükleri konusunda bilgiye sahip olmadıklarını göstermektedir. $\mathrm{Bu}$ durum projenin başarısı için olumsuz olup konuyla ilgili bilgi eksikliğinin giderilmesi projenin sürdürülebilirliği açısından önemlidir.

Çizelge 3. GÇP'den haberdar olma ve başvuruya ilişkin genel bilgiler.

Table 3. Awareness of the YFP and general information for application.

\begin{tabular}{|c|c|c|c|}
\hline \multicolumn{2}{|c|}{ GÇP'ne ilişkin bilgiler } & \multirow{2}{*}{$\begin{array}{c}\text { Sayı } \\
51\end{array}$} & \multirow{2}{*}{$\begin{array}{c}\% \\
40.2\end{array}$} \\
\hline \multirow{4}{*}{ Projeden haberdar olma kaynağı } & İl/İlçe Müdürlüğü & & \\
\hline & İnternet/TV/Gazete vb. & 68 & 53.5 \\
\hline & Projeden hibe alanlar & 8 & 6.3 \\
\hline & Toplam & 127 & 100.0 \\
\hline \multirow{5}{*}{ Hibe desteği almada etkili olan kişi } & Kendisi & 73 & 57.5 \\
\hline & Kendisi ve eşi & 50 & 39.4 \\
\hline & Aile Büyükleri (Anne, baba, vs.) & 3 & 2.3 \\
\hline & Diğger (Yakını) & 1 & 0.8 \\
\hline & Toplam & 127 & 100.0 \\
\hline \multirow{5}{*}{ Projeye başvurma nedeni } & İşsizlik & 18 & 14.2 \\
\hline & Ailenin teşviki & 8 & 6.3 \\
\hline & Gelirini arttırmak için & 95 & 74.8 \\
\hline & Çocuklarının geleceği için & 6 & 4.7 \\
\hline & Toplam & 127 & 100.0 \\
\hline \multirow{4}{*}{$\begin{array}{l}\text { Proje başvuru sürecinden önce hazırlık yapma } \\
\text { durumu }\end{array}$} & Evet & 108 & 85.0 \\
\hline & Hayır & 17 & 13.4 \\
\hline & Kismen & 2 & 1.6 \\
\hline & Toplam & 127 & 100.0 \\
\hline \multirow{4}{*}{ Destek almada karşılaşılan zorluklar } & Başvuru şartları & 39 & 30.7 \\
\hline & Maddi imkânsızlıklar & 17 & 13.4 \\
\hline & Bürokratik engeller & 71 & 55.9 \\
\hline & Toplam & 127 & 100.0 \\
\hline
\end{tabular}


Araştırma kapsamında görüşülen çiftçilerin \%22.8'i GÇP programına dahil olmasa bile işletmeyi yinede kuracaklarını belirtirken, \%62.2'si ise proje olmasa kuramayacaklarını belirtmişlerdir. Nitekim araştırma sonuçlarına göre çiftçiler sera tesisinin ancak 1000-1500 $\mathrm{m}^{2}$ lik kısmını hibe desteği ile yaptıklarını ifade etmişlerdir. Adana ilinde yürütülen bir çalışmada ise çiftçilerin \%95.4'ü GÇP olmasa işletme kuramayacaklarını ifade etmişlerdir (TOB 2018c). Bu sonuçlar, GÇP'nin yeni işletme kurulması açısından önemli olduğunu ortaya koymaktadır. $\mathrm{Bu}$ durum GÇP projesinin amaçlarına ulaşması ve sürdürülebilirliği açısından olumludur.

Araştırma kapsamındaki çiftçilerin \%65.4'ü GÇP'yi kısmen yararlı, \%18.9'u yararlı bulurken, \%15.7'si ise projenin yararlı olmadığını düşünmektedirler. Bu kapsamda çiftçilerin yaklaşık \%84'ü GÇP'nin üretime katkı sağladığını belirtirken \% $\% 15.7$ 'si ise üretime katkısının olmadığ düşüncesindedirler. Diğer yandan çiftçilerin \%66.1'i hibe desteği sayesinde mevcut üretimini artırırken, \%14.2'si ilk defa üretime başlamıștır. Bu sonuçlar, çiftçilerin büyük bir çoğunluğunun projeyi yararlı bulduklarını göstermektedir.

Dolayısıyla GÇP projesinin tarımsal üretimin sürdürebilirliği açısından önemli bir proje olduğu söylenebilir. Ancak GÇP'nin yeni işletme kurmaktan ziyade mevcut üretim faaliyetinin büyütülmesine katk1 yaptığ 1 ifade edilebilir. Bu nedenle projeyle verilen hibe miktarının arttırılması ve günün koşullarına göre gerekli iyileştirmelerin yapılmasına ihtiyaç bulunmaktadır. Nitekim çiftçilerin \%48.0'i hibe miktarının arttırılmasını, \%52.0'si ise destekleme verilen çiftçi sayısının arttırılmasını ifade etmişlerdir.

Görüşme yapılan çiftçileri yaşadıkları yere (mahalle/köy) bağlayan en önemli nedenin (\%95.3) doğduklarından beri aynı yerde yaşamalarıdır. Çiftçiler buna neden olarak büyük bir çoğunlukla (\%71.9) köyde yaşamayı sevdiklerini belirtmişlerdir. Nitekim çiftçilerin sadece \%13'ü şehire göç etme düşüncesindedir. Şehire göç etmeyi düşünen çiftçiler bu durumun en büyük nedeni olarak üretim maliyetlerinin fazla olmasını göstermişlerdir.

GZFT tablosu oluşturulurken, GÇP'ye ilişkin ortalamanın üstünde pozitif düşünceler GÇP'nin güçlü yönler ve firsatları olarak ortalamanın altındaki düşünceler; zayıf yönleri, tehditleri ve geliştirilmesi gereken noktaları işaret etmesi referans alınmıştır.

GÇP uygulaması ve etkilerine göre GZFT analizinde ise düşüncelerde güçlü yönlerden en yüksek ortalamaya sahip 4.65 ile "hibe alım sürecinin şeffaflığı" olduğu ifade edilmiştir. Bunu 4,08 ortalama ile "kırsal alan yaşlanmasına çözüm olması" kriteri projenin güçlü yönlerinden birisi olarak öne çıkmaktadır. Bunun yanında firsatlarda en yüksek 4.13 ortalama ile "ürün kalitesi markalaşması adına yapıcı adımlar atılması potansiyeli olması" kriteri olurken, bunu 4.05 ortalama ile "gençleri çiftçiliğe ve kırsala özendirmesi ve gıda güvenliği, gıda güvencesi" ve "gıda bağımsızlığına olumlu katkı sunma potansiyeli" olması kriterleri firsatlar olarak takip etmiştir (Çizelge 4).

GÇP uygulamasında karşılaşılan sorunlar ve risklere göre GFZT analizinde ise güçlü yönlerden en yüksek ortalama sahip olan unsur 3.27 ile "proje uygulama süresi yeterlidir" kriteridir. $\mathrm{Bu}$ kriteri 3.18 ile "işletme ve ürün sigortalama miktarı uygundur" ve 3.16 ile "danışmanlık hizmeti alınmaktadır" kriterleri izlemiştir. Zayıf yönlerde mevcut durum değerlendirmesinde en yüksek ortalama 4.89 ile "hibe alım sürecinde istenilen şartlar fazlalığı" olup bunu 4.72 ortalama ile "verilen hibe oranı yetersizliği" kriteri takip etmiştir (Çizelge 5). Çalışma kapsamında çiftçilerden elde edilen bulgulardan oluşturulan GZFT analizi Çizelge 6'da verilmiştir. Buna göre çiftçiler GÇP'nin güçlü yönlerini ve firsatlarını, projenin zayıf yönleri ve tehditlerinden daha olumlu olarak değerlendirilmektedir.

Çizelge 4. GÇP uygulaması ve etkileri hakkında (GZFT analizi).

Table 4. About YFP application and its effects (SWOT analysis).

\begin{tabular}{|c|c|c|}
\hline Düşünceler & Ortalama & GZFT \\
\hline Proje kapsamında hibe almanın kolaylığı & 2.25 & $\mathrm{Z}$ \\
\hline Hibe alım sürecinin şeffaflığı & 4.65 & G \\
\hline Hibelerin zamanında ödenmesi & 2.67 & $\mathrm{Z}$ \\
\hline Proje hibesinin katkı yapması & 3.94 & G \\
\hline Projenin etkin ve verimli olması & 3.45 & $\mathrm{G}$ \\
\hline Hibe miktarının düşük bulunması & 4.93 & $\mathrm{~T}$ \\
\hline Gelir artışı, gelir istikrarı, gelir çeşitlenmesi sağlamaması & 3.72 & $\mathrm{~T}$ \\
\hline Bilinçli çiftçiliğe katkı sunması & 3.92 & $\mathrm{~F}$ \\
\hline Bilişim inovasyon teknoloji kullanımına yarar sağlaması & 3.68 & $\mathrm{~T}$ \\
\hline Sadece üretim sürdürülebilirliğine katkısının olması & 4.02 & $\mathrm{Z}$ \\
\hline Kırsal alan yaşlanmasına çözüm olması & 4.08 & G \\
\hline $\begin{array}{l}\text { İklim, çevre kalitesi, su yönetimi, mera yönetimi, ekolojik su-karbon ayak izine ilişkin etkiler gösterme } \\
\text { potansiyeli olması }\end{array}$ & 3.96 & $\mathrm{~F}$ \\
\hline Ürün kalitesi markalaşması adına yapıcı adımlar atılması potansiyeli olması & 4.13 & $\mathrm{~F}$ \\
\hline Gıda güvenliği, gıda güvencesi ve gıda bağımsızlığına olumlu katkı sunma potansiyeli olması & 4.05 & $\mathrm{~F}$ \\
\hline Gençleri çiftçiliğe ve kırsala özendirmesi & 4.05 & $\mathrm{~F}$ \\
\hline Kırsalda hareketlilik yaratmaktadır ve kırsal yaşamı özendirmektedir & 3.69 & $\mathrm{~F}$ \\
\hline Gençlerin girişimci olmasına katkı sağlaması & 4.04 & $\mathrm{~F}$ \\
\hline Üretime olumlu katkı sağlaması & 3.85 & $\mathrm{~F}$ \\
\hline Genel Ortalama & 3.83 & \\
\hline
\end{tabular}


Çizelge 5. GÇP uygulamasında karşılaşılan sorunlar ve riskler (GZFT analizi).

Table 5. Problems and risks encountered in YFP implementation (SWOT analysis).

\begin{tabular}{lcc}
\hline Düşünceler & Ortalama \\
\hline Proje uygulama süresi yetersizliği & 3.27 \\
Verilen hibe oranı yetersizliği & 4.72 \\
Hibe alım sürecinde istenilen şartlar fazlalı̆̆ı & GZF \\
İstenilen gider kalemlerinin maliyeti fazlalı̆̆ı & 4.89 \\
İşletme ve ürün sigortalama miktarı fazlalığı & 4.98 \\
Danışmanlık hizmeti alınmaması & 3.18 \\
Ürün pazarlaması yetersizliği & 3.16 \\
İşçi ücretleri fazlalığı & 3.22 \\
Aile işgücü yetersizliği & $\mathrm{Z}$ \\
Ürün fiyatları yetersizliği & $\mathrm{T}$ \\
Girdi maliyetleri yüksekliği & $\mathrm{G}$ \\
Tarım alet ve ekipmanları yetersizliği & $\mathrm{G}$ \\
Hastalıklardan dolayı ürün kaybı yaşanması & $\mathrm{G}$ \\
Doğal afetlerden dolayı ürün veya işletme zarar görmesi & $\mathrm{G}$ \\
\hline Genel Ortalama & $\mathrm{T}$ \\
\hline
\end{tabular}

Çizelge 6. GZFT analizi sonuçları.

Table 6. SWOT analysis results.

\section{GÜCCLÜ YÖNLER (G)}

- G1. Hibe alım süreci şeffaf olması.

- G2. Kırsal alan yaşlanmasına çözüm olması.

- G3. Proje hibesinin katk1 yapması.

- G4. Projenin etkin ve verimlidir.

- $\quad$ G5. Proje uygulama süresi yeterli olmasi.

- G6. Ürün pazarlamasının yeterli olması.

- G7. Tarım alet ve ekipmanları yeterli olması.

- G8. İşçi ücretleri uygun olmasi.

- G9. İșletme ve ürün sigortalama miktarı uygun olması.

- G10. Danışmanlık hizmeti alınması.

- G11. Hastalıklardan dolayı ürün kaybı yaşanmaması.

- G12. Aile işgücünün yeterli olması.

- G13. Doğal afetlerden dolayı ürün veya ișletme zarar görmemesi.

\section{FIRSATLAR $(\mathbf{F})$}

- F1. Ürün kalitesi markalaşması adına yapıcı adımlar atılmasını sağlayabilir olması.

- F2. G1da güvenliği, gida güvencesi ve g1da bağımsızlığına olumlu katkı sunabilmesi.

- $\quad$ F3. Gençleri çiftçiliğe ve kırsala özendirmesi.

- F4. Gençlerin girişimci olmasına katkı sağlaması.

- F5. İklim, çevre kalitesi, su yönetimi, mera yönetimi, ekolojik sukarbon ayak izine ilişkin etkiler gösterme potansiyelinin olması.

- F6. Bilinçli çiftçiliğe katkı sunması.

- $\quad$ F7. Üretime olumlu katkı sağlaması.

- F8. Kırsalda hareketlilik yaratması ve kırsal yaşamı özendirmesi

\section{Sonuç}

Bu çalışmada, Antalya ilinde Genç Çiftçi Projesi (GÇP) uygulaması ve projenin sürdürülebilirlik açısından bir değerlendirmesinin yapılması amaçlanmıştır. Çalışma kapsamında GÇP'nin çiftçilerin girişimciliğini desteklenmesi, gelir düzeyini yükseltilmesi, tarımda sürdürülebilirliğin sağlanması ve kırsalda genç nüfusun istihdamına katkı sağlaması gibi amaçlara ulaşılabilme potansiyeli genç çiftçilerden elde edilen veriler sşı̆̆ında incelenmiştir.

Görüşme yapılan çiftçilerin yaklaşık \%85 gibi büyük bir çoğunluğu GÇP'ni yararlı görmektedir. Ancak hibe desteği sayesinde üretime başladığını söyleyen çiftçilerin oranı sadece $\% 14.2$ olarak bulunmuştur. Bu sonuç, GÇP proje desteğinin

\section{ZAYIF YÖNLER (Z)}

- Z1. Hibe alım sürecinde istenilen şartların fazla olması

- Z2. Verilen hibe oranı yetersiz olması.

- Z3. Sadece üretim sürdürülebilirliğine katkısı olması.

- Z4. Hibelerin zamanında ödenmesinde problem yaşanması.

- Z5. Proje kapsamında hibe almanın zor olması. yeni bir işletme kurulması açısından yeterli olmadığını göstermektedir. Buna karşın proje desteği ile mevcut üretimini arttırdığını belirten çiftçilerin oranı \%66.1 olarak bulunmuştur. Dolayısıyla GÇP kapsamında verilen hibe desteğinin yeni bir işletme kurulmasından çok mevcut işletmeye destek olduğunu göstermektedir.

Araştırma sonuçlarına göre GÇP'nin yeni işletme kurulması açısından, tarımsal üretimin sürdürebilirliği açısından önemli ve gerekli bir proje olduğu söylenebilir. Bu nedenle GÇP'nin öngörülen amaçlarına ulaşma potansiyeli taşımaktadır. Bunun yanında araştırmadan elde edilen bulgulara göre projenin bazı yetersiz yönleri de bulunmaktadır. 
GÇP hibe başvuru sürecinde istenilen şartların çok fazla olması, bürokratik işlemlerin uzun sürmesi ve proje kapsamındaki tesis yapım maliyetinin yüksek olması çiftçilerin önemli sorunları arasındadır.

Diğer yandan GÇP kapsamında çiftçi başına verilen 30.000 TL'lik hibe desteğinin, yetersiz olduğu belirlenmiştir. Bu nedenle GÇP kapsamında verilen hibe miktarının yükseltilmesi ve ekonomik koşullara göre güncellenmesi projenin amaçlarına ulaşabilmesi için önemli ve gereklidir. Nitekim çiftçilerin \%52'si verilen giderler için verilen destekleme miktarının arttırılmasını, \%48'i ise hibe miktarının arttırılmasını ifade etmişlerdir.

Çiftçilerin proje kapsamındaki tarımsal üretimi sürdürebilir ve kârlı bir şekilde yapması, tarımsal üretim faaliyetleri ile ilgili eğitim ve danışmanlık hizmeti almaları önemlidir. Bu nedenle üretim pazarlama konusunda danışmanlık hizmetinden faydalanması için proje kapsamında danışman desteği verilmesi tartışılmalıdır.

Sonuç olarak; GÇP'nin tarımda sürdürülebilirlik, gençlerin çiftçiliğe özendirilmesi ve ülke tarımının güvence altına alınması gibi amaçlarına ulaşabilmesi için hibe destek miktarının yeterli hale getirilmesi ve ekonomik koşullara göre güncellenmesi, desteklenen çiftçi sayısının arttırılması, bilinçli tarım faaliyetleri için danışmanlık ve eğitim çalışmalarının etkin bir şekilde yapılması GÇP'nin başarıya ulaşması için büyük önem taşımaktadır.

\section{Kaynaklar}

Çoban B, Karakaya E Y (2010) Geleceği Planlamada Stratejik Yönetim ve Swot Analizi: Kavramsal Yaklaşımlar. E-Journal of New World Sciences Academy 5(4): 342-352.

Sav O, Sayın C (2015) Sebze Tohumculuk Sektörünün SWOT Analizi ile İncelenmesi: Antalya İli Örneği. Tarım Ekonomisi Araştırmaları Dergisi 1(1): 17-28.

TCRG (2016) Kırsal Kalkınma Destekleri Kapsamında Genç Ciftçi Projelerinin Desteklenmesi Hakkında Tebliğ (Tebliğ No: 2016/16), 5 Nisan 2016 tarihli ve 29675 sayılı Resmi Gazete.

TOB (2017) Genç Çiftçi Projesi Başvuru Detayları. Tarım ve Orman Bakanlığı Antalya İl Tarım ve Orman Müdürlügü, Antalya.

TOB (2018a) Genç çiftçi projesine 378 bin başvuru. https://www.tarimorman.gov.tr/Haber/963/genc-ciftci-projesine378-bin-basvuru-. Erişim 20 Ocak 2018.

TOB (2018b) Genç Çiftçi Projesi. https://gencciftci.tarim.gov.tr/. Erişim 17 Eylül 2018.

TOB (2018c) Genç Çiftçi Hibe Destekleri Etki Analizi. Adana İl Gıda Tarım ve Hayvancıllk Müdürlügü, Adana.

Unakıtan G ve Başaran B (2018) Genç Çiftçi Projesinin Başarısı İçin Bir Öneri: Genç Çiftçi Kooperatifleri. Balkan ve Yakın Doğu Sosyal Bilimler Dergisi 04(02): 149-157. 